\title{
26
}

\section{Identifying a Representative Year of Precipitation in Support of a Wet Weather Plan}

\author{
Sangameswaran Shyamprasad, Khalid N. Khan, \\ Gary Martens and James T. Smullen
}

In support of a regional wet weather plan, computer models have been developed to simulate baseline conditions to establish the frequency and duration of combined sewer overflow (CSO) and sanitary sewer overflow (SSO) discharges, the potential water quality impacts they produce, and to develop and assess alternative control strategies. Much of the uncertainty in a carefully constructed hydrologic and hydraulic model is derived from uncertainty in the rainfall record. Therefore, increasing the level of detail of the rainfall input, both spatially and temporally, increases the accuracy and precision of the model results. Careful attention to rainfall collection and analysis is critical to the modeling effort. The refinement of precipitation data becomes an important process because precipitation is the driving force that increases wastewater flow along sewers and transports pollutants via CSO and SSO discharges to receiving waters.

The U.S. Environmental Protection Agency CSO Control Policy (1994) requires the characterization of the combined sewer system area and evaluation of control measure performance using the complete rainfall record for the geographic area of its existing combined sewer systems (CSS) using sound statistical procedures. However, for most US cities historical precipitation data is available for periods anywhere from fifty to hundred years. It is not possible to run complex and large models for all the years for which precipitation data is

Shyamprasad, S., K. Khan, G. Martens and J. Smullen. 2010. "Identifying a Representative Year of Precipitation in Support of a Wet Weather Plan." Journal of Water Management Modeling R236-26. doi: 10.14796/JWMM.R236-26.

(C) CHI 2010 www.chijournal.org ISSN: 2292-6062 (Formerly in Dynamic Modeling of Urban Water Systems. ISBN: 978-0-9808853-3-0) 
available and hence it is imperative that a short period of few years or a typical year, which is truly representative of long term hydrological conditions, be selected from the larger precipitation dataset.

The selected representative year, based upon quality assured long term local precipitation data, should be able to produce annual CSO statistics such as volume, duration and event frequency that closely match the long term historical average. Ideally, representative periods would be selected by running the model for a long term simulation based upon long term high-quality local precipitation data and selecting periods that produce annual CSO volume, duration and number of CSO events closest to the mean. The CSO events should also have a representative seasonal distribution in order to assure the validity of applying the results to receiving water studies. Since it would be time-consuming to run the complex model for many years, surrogate techniques can be used in the selection process.

CSO occurrence is considered to be a complex function of storm event characteristics such as total volume, duration, peak intensity and length of antecedent dry period or inter-event time (IET). Continuous 12 month periods selected from the recent quality assured radar rainfall data were evaluated against the long term record based on storm event characteristics such as annual event frequency, total annual rainfall volume and event peak hourly rainfall intensity. Statistical analyses were conducted to determine adjustments to the actual 12 month rainfall that were necessary to eliminate bias against historical record average values.

This chapter presents a statistical analysis approach including double-mass regression and cumulative distribution frequency (CDF) analysis of long term regional rain gauge data and high resolution short term radar rainfall data to establish a representative one-year precipitation record.

\subsection{Available Data Sources for the Analyses}

Since the main focus of this study is to select a representative year precipitation for supporting a wet weather plan, a combined sewer system (CSS) service area was selected to demonstrate the approach. Three principal sources of precipitation data were utilized to conduct this representative precipitation year analysis for this service area.

The long term historical record dataset was obtained from the National Weather Service Cooperative located within the service area. Hourly data were obtained and utilized for the 60 y period 1949-2008. These data were used for calculating the historical average annual and average monthly precipitation 
statistics, such as total volume and event frequency. The data were also used to calculate historical average event statistics such as storm volume, peak storm intensity, storm duration, and storm inter-event time.

A second long term historical record is available from the National Weather Service Cooperative Station that was located within the service area. Hourly precipitation data were recorded from October 1952 through September 1979. The gauge site is approximately $13 \mathrm{mi}(20.8 \mathrm{~km})$ east of the airport gauge. The rainfall record from both locations was analyzed and compared for the $25 \mathrm{y}$ period of overlapping record to determine if the difference in locations would make a difference in long term average rainfall.

A network of recording precipitation gauges was established in April 2000 in support of a regional radar rainfall system that provides a high resolution spatially distributed precipitation dataset. The gauges have heating elements in the collection funnels. Snowfall is monitored as an equivalent water volume. The gauge network is currently comprised of 33 sites that record precipitation in 15 min increments. The gauge datasets were collected through December 2008 and analyzed to establish short term hydrological characteristics.

Gauge-adjusted radar rainfall dataset was available for the period from April 1, 2000 through December 31, 2008. The regional radar-rainfall system utilizes Doppler weather radar data collected at the airport, adjusts the reported reflectivity values to the rainfall data obtained from the network of regional gauges, and reports precipitation in $15 \mathrm{~min}$ increments. The calculated precipitation data are provided as a continuous time series assigned to a $1 \mathrm{~km} \mathrm{x} 1 \mathrm{~km}$ pixel grid that was superimposed over the service area. The time series data from 872 pixels are needed to provide coverage for the $310 \mathrm{mi}^{2}\left(801 \mathrm{~km}^{2}\right)$ service area. These pixel datasets were obtained and analyzed to identify the spatial and temporal variation in the precipitation associated with each of the catchment areas simulated by the hydraulic and hydrologic models. The statistical annual storm event results from these analyses were compared with corresponding long term statistics from the historical gauge dataset to screen and select the best representative precipitation year.

\subsection{Long Term Hydrological Conditions Analyses}

The first step in the process of developing a representative year dataset for the service area is to characterize long term precipitation and develop statistics which will serve as selection criteria in the screening and evaluation processes. Long term precipitation conditions over the service area were characterized using the historical hourly precipitation record for a 60 y period 1949-2008 
obtained from the National Weather Service Cooperative Station located at a nearby international airport. Statistical analyses of the long term record at the airport gauge were performed to determine the average frequency, volume, peak intensity, duration, and inter-event times (IETs) of rainfall events.

Figure 26.1 shows the annual precipitation volume for each year in the long term record along with the historical annual average value of $36.79 \mathrm{in}$. (93.45 $\mathrm{mm}$ ). Also shown are the plus or minus one standard deviation values that depict the statistical $68 \%$ confidence intervals for the dataset. The figure shows that total annual rainfalls during years such as 2004, 1990 and 1956 were significantly greater than average, characterizing them as wet years. Conversely, the annual rainfalls during years such as 1995, 1988 and 1963 were significantly less than average, characterizing them as dry years. The selected representative year should have a total annual rainfall as close as possible to the annual average of the historical record.

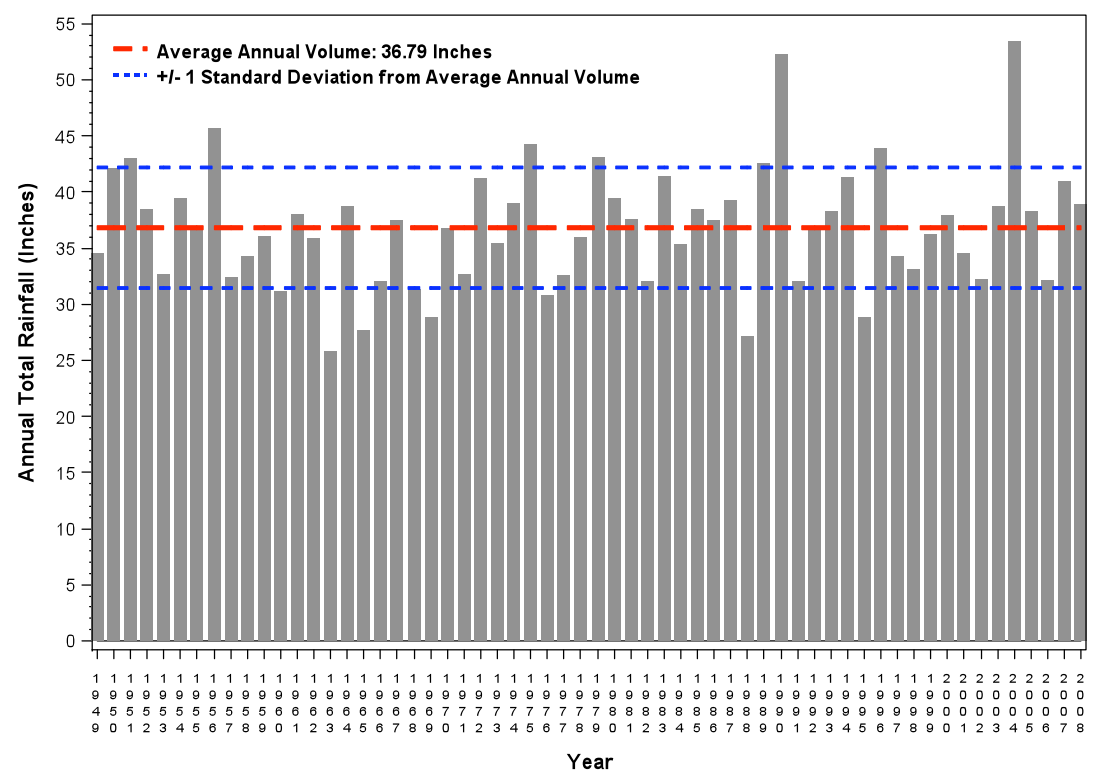

Figure 26.1 Long term annual precipitation volumes at the airport gauge.

Figure 26.2 shows the annual total of significant precipitation events and the corresponding historical annual average. A threshold value of 0.05 in. (1.27 $\mathrm{mm}$ ) and an inter-event period of $6 \mathrm{~h}$ were used to define significant precipita- 
tion events. The threshold value roughly corresponds with the depression storage values used in the SWMM models and approximates the minimum rainfall at which runoff commences from impervious surfaces. Any storms that stopped and restarted within $\leq 6 \mathrm{~h}$ were considered a single event. The analyses indicated that the average number of significant precipitation events over the long term record was 94 events. Also shown on the figure are the plus or minus one standard deviation values that depict the statistical $68 \%$ confidence intervals for the dataset. The figure shows that the total number of events during years such 1996, 1990 and 1972 was significantly greater than average. Conversely, the total number of events during years such as 2006, 1999 and 1960 was significantly less than average. The selected representative year should have a total number of significant precipitation events as close as possible to the annual average of the historical record.

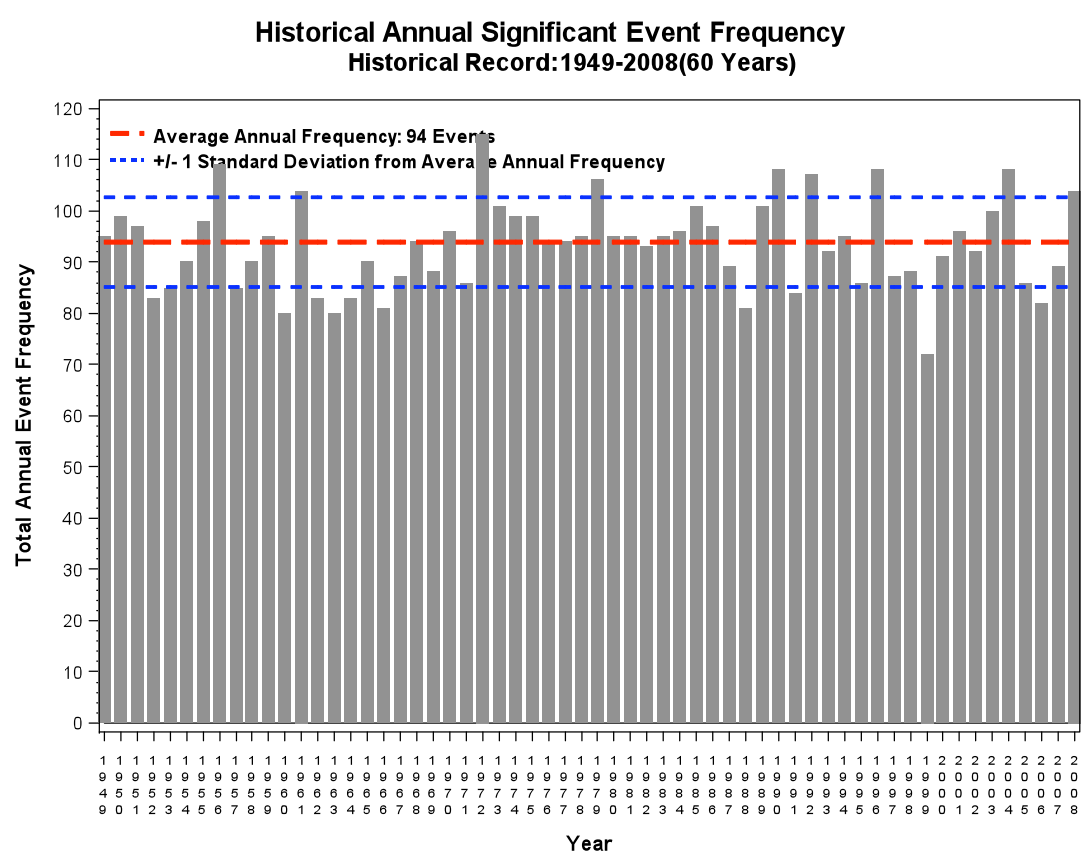

Figure 26.2 Long term annual total number of significant events at the airport gauge.

Figure 26.3 shows the average monthly distribution of rainfall volume based upon the $60 \mathrm{y}$ historical data record from the airport gauge. Also included are 
the $68 \%$ confidence intervals associated with plus and minus one standard deviation from the monthly mean values. The period May-August typically experiences the largest precipitation volumes for an average year and the period October-February typically experiences the smallest precipitation volumes.

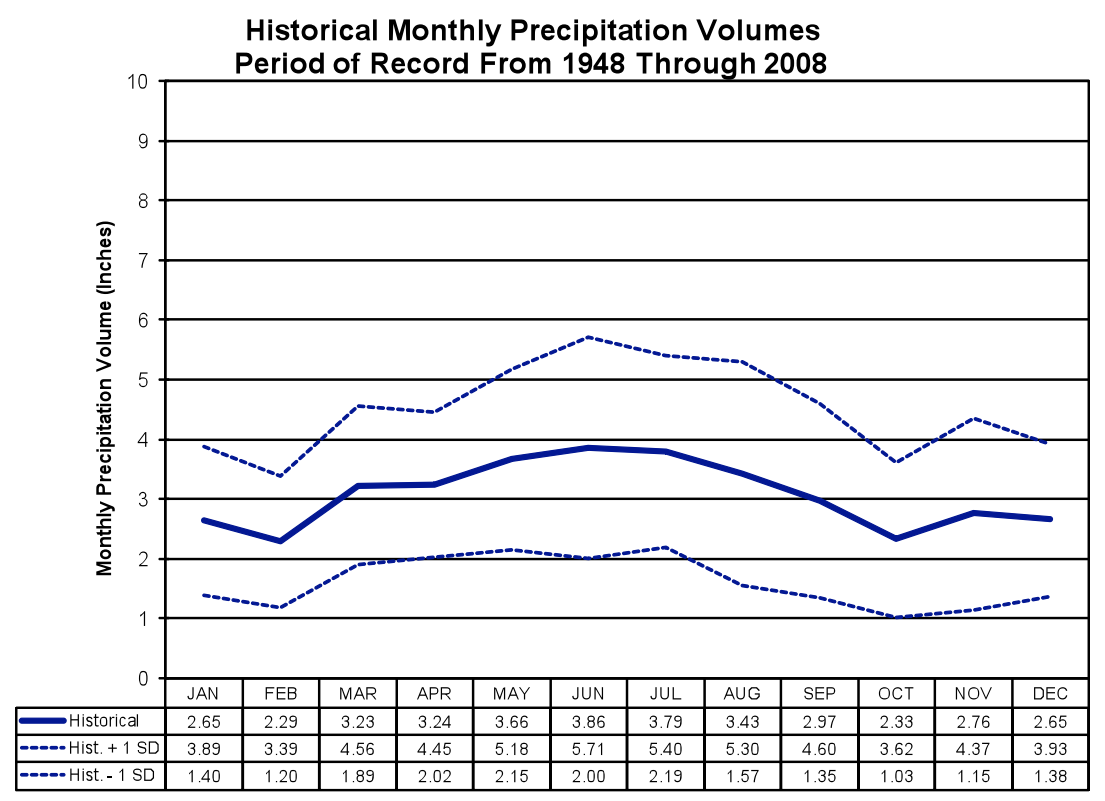

Figure 26.3 Average monthly precipitation volumes.

Figure 26.4 shows the average monthly distribution of event frequency in a representative year, based upon a minimum event volume of 0.05 in. (1.27 $\mathrm{mm})$. Also shown on the figure are the \pm 1 standard deviation values. The figure shows that precipitation events in the greater region tend to be distributed relatively evenly throughout the year, averaging from 5 events/month to 7 events/month. The selected representative year should have a monthly distribution of precipitation volume as close as possible to the historical record. 


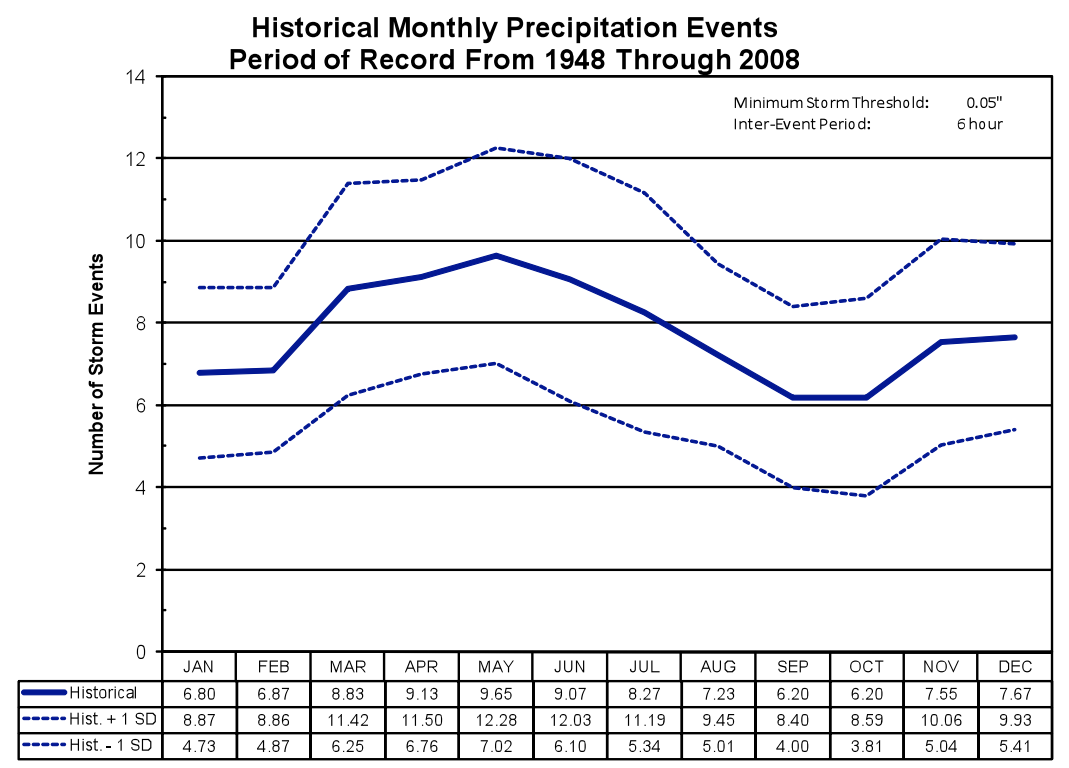

Figure 26.4 Average number of monthly precipitation events.

\subsection{Spatial Distribution Analyses}

The spatial distribution of precipitation over the service area was assessed and characterized using the gauge-adjusted high resolution radar rainfall data that extends from April 2000 through December 2008. It is important to note that while the radar-rainfall system provides a continuous time series in $15 \mathrm{~min}$ increments for each of the pixels within the geo-referenced grid, the detailed radar reflectivity versus precipitation analyses are performed only when the minimum criterion is met as explained below. To be classified and analyzed as a radar-rainfall event, during any given hour at least $50 \%$ of all functioning rain gauges must record an accumulation of at least $0.05 \mathrm{in} .(1.27 \mathrm{~mm})$ precipitation. The precipitation occurring during the times between the significant events (that meet the threshold criteria) is estimated by applying an inverse distance square weighting method to the regional rain gauge data for the gauge site locations surrounding given pixel. This gauge filling by step provides a continuous time series of precipitation for each pixel. The individual pixel precipitation is then transformed to a virtual rain gauge time series for each catchment or subcatchment area simulated by the hydrologic and hydraulic models. The gauge filled continuous rainfall for each pixel is area weighted by the sub-catchments 
to compute a precipitation time series for each sub-catchment. This process creates a unique virtual rain gauge for each sub-catchment in the service area.

The CSS area was further divided into eight planning basins. To characterize the spatial distribution of precipitation, annual event statistics were calculated for each of these planning basins. Annual event statistics for total storm volume, peak hourly storm intensity, storm duration and inter-event time were generated for each virtual rain gauge and the results were averaged over each of the planning basin to compute the basin event statistics.

\subsection{Initial Screening Assessment}

The spatially distributed radar rainfall dataset, extending from April 2000 through December 2008, was analyzed to identify and select the 12-continuousmonth periods which best matched the long term annual average precipitation volume and annual average total annual number of significant events ( $<0.05 \mathrm{in}$. with a $6 \mathrm{~h}$ inter-event period). Since the representative year will be eventually used in the water quality analysis, care was taken to neither start nor end the 12continuous-month period during a growing season. Based on this constraint, the months of January, May and October were selected as acceptable starting months, resulting in 22 alternative 12-month-long planning year datasets to screen. For example, the period May 2000-April 2001 was denoted as planning year May2000, and similarly the period October 2002-September 2003 was planning year Oct2002.

As explained previously, the annual total volumes and event frequencies were computed for each virtual gauge assigned to a sewershed or subcatchment area and then averaged over each of the designated planning basin areas. These planning basin event volumes and frequencies were compared to the long term annual average volume (36.79 in. [93.45 mm]) and average total annual number of events ( 94 events $<0.05$ in. [ $1.27 \mathrm{~mm}]$ ) to identify the 12 continuous-month period that best matched the long term averages from the historical airport gauge record.

The annual event volumes and frequencies were chosen as the primary screening criteria to conduct the initial screening assessment. The event statistics were computed for each of the 22 alternative planning years for the airport gauge and all of the virtual catchment area gauges which were averaged over each of the planning basins. Bar charts were developed to compare the planning year precipitation totals and number of events to the historical annual average volume and annual average frequency. Figures 26.5(a) and (b) show the bar charts used to display the analysis results for the total annual number of events 
comparisons. The horizontal line on Figure 26.5(a) represents the long term annual average number of 94 events with an event depth $>.05$ in. $(1.27 \mathrm{~mm})$. Each bar represents the annual event count for the airport gauge and each of the planning basin areas. The bars are grouped by each of the 22 alternative planning years that were evaluated. Figures 26.6(a) and (b) show the bar charts used to display the analysis results for the annual precipitation volume comparisons. The horizontal line on Figure 26.6 represents the long term average precipitation volume of 36.79 in. $(93.45 \mathrm{~mm})$.

It can be noted from Figure 26.5 that alternative candidate planning years from May2000 through May2002 and from Oct2004 through May2007 have considerably fewer events when compared to the long term average. This leaves six candidate planning years, from Oct2002 through May2004, where the annual number of precipitation events with a volume $\geq 0.05$ in. $(1.27 \mathrm{~mm})$ are reasonably close to the historical average number of events. When Figure 26.6 is reviewed for individual basin total volumes, it is evident that there are several datasets with a total annual volume reasonably close to the long- term average. However, only the six candidate planning years from the event

Average Sewershed Precipitation May 2000 - September 2004

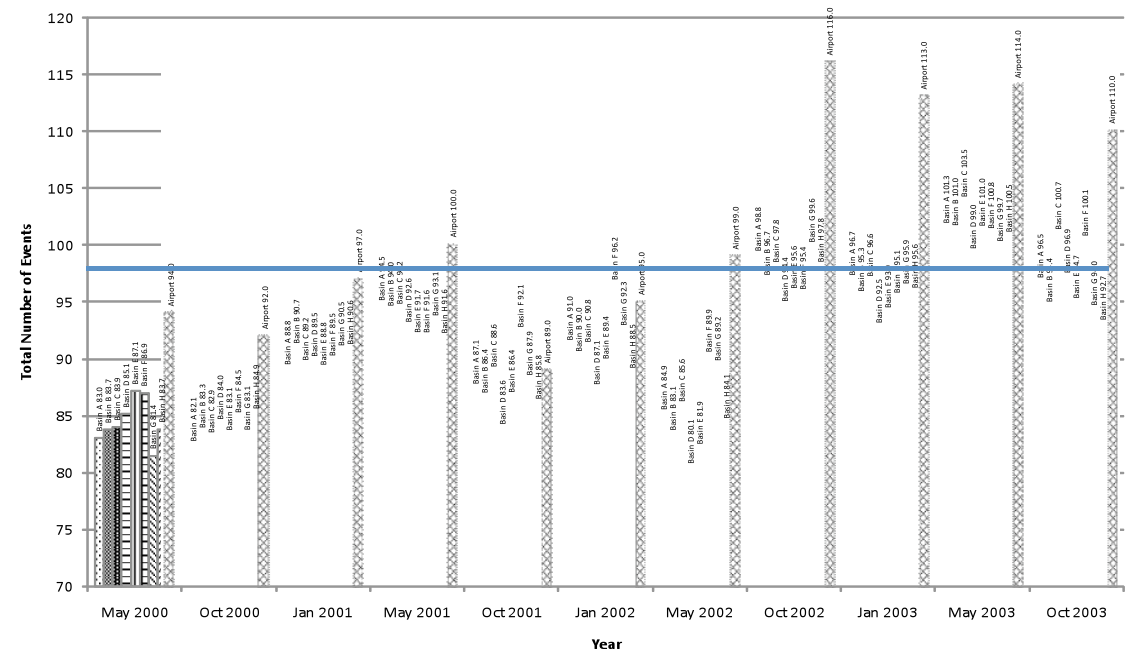

$\left[\begin{array}{ll}\mathrm{B} \\ \mathrm{B} a \sin \mathrm{A}\end{array}\right.$

Figure 26.5(a) Total number of events for all basins by year. 
Average Sewershed Precipitation January 2004 - April 2008

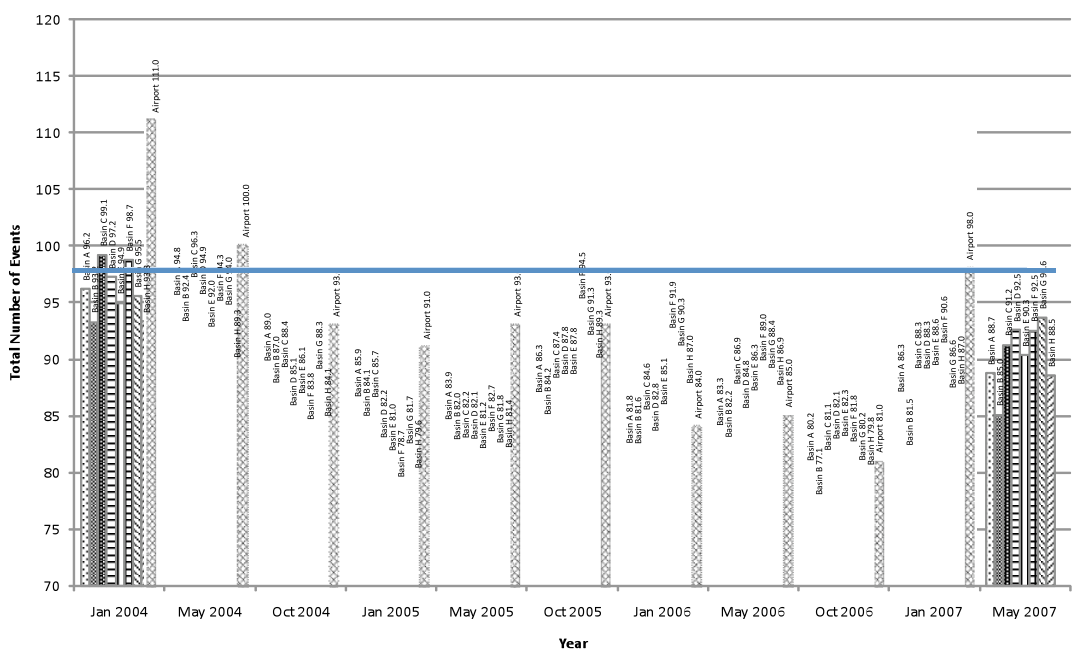

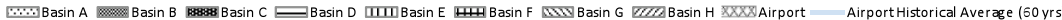

Figure 26.5(b) Total number of events for all basins by year.

Average Sewershed Precipitation May 2000 - September 2004

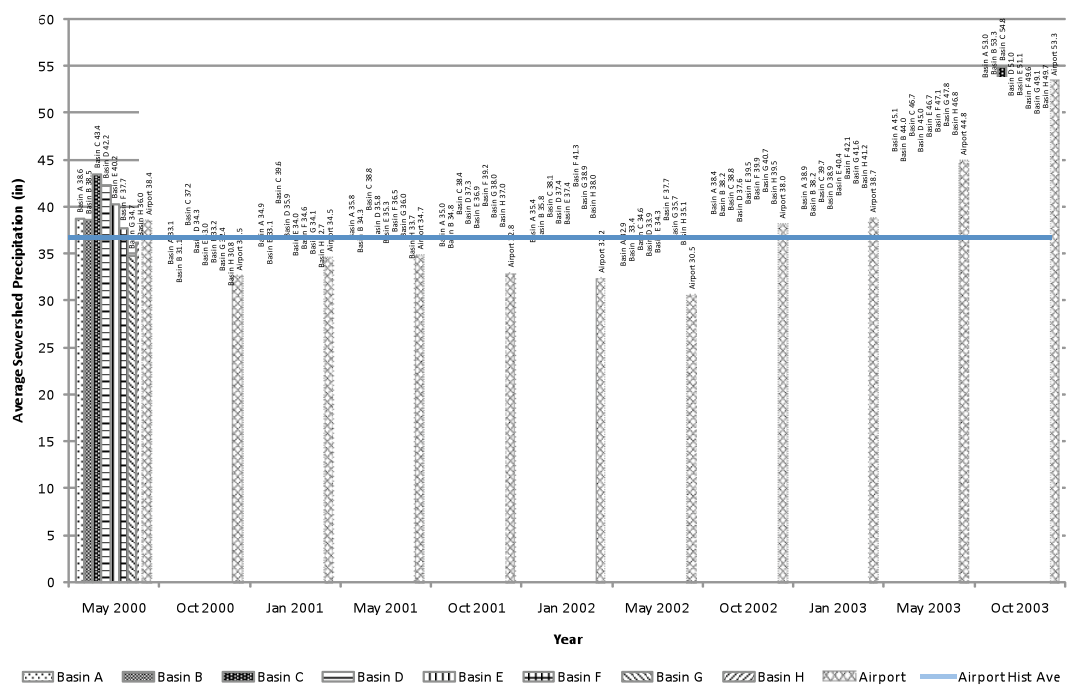

Figure 26.6(a) Total rainfall volume for all basins by year. 
Average Sewershed Precipitation January 2004 - April 2008

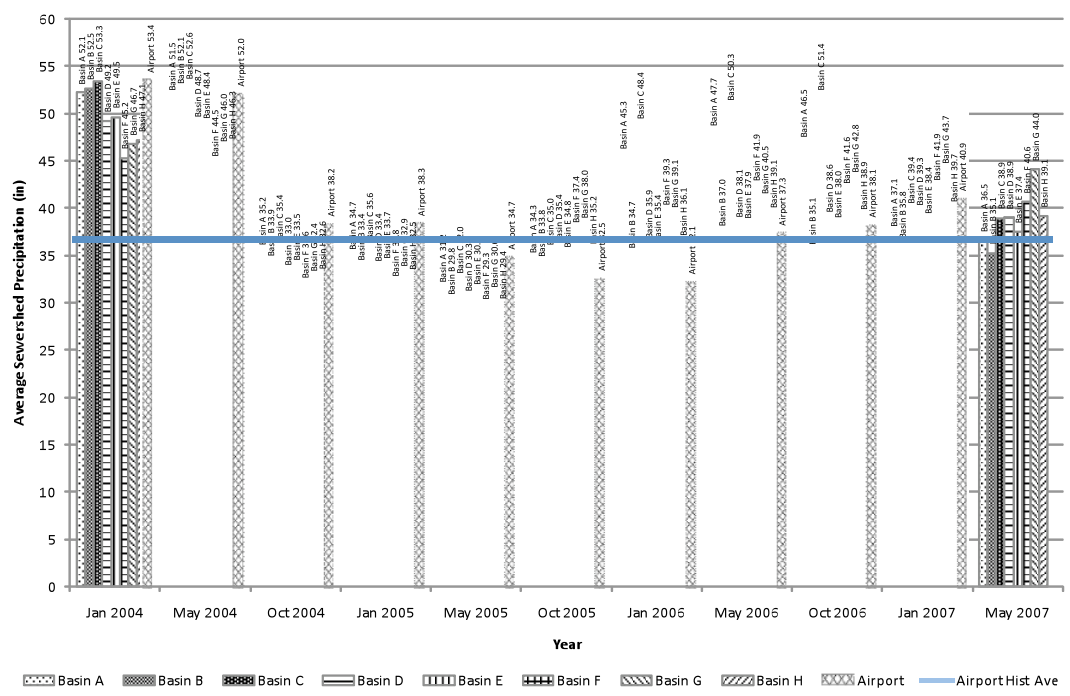

Figure 26.6(b) Total rainfall volume for all basins by year.

frequency screening analyses were considered. Of these candidate planning years, May2003 through May2004 have considerably more volume than the long term average, leaving Oct2002 and Jan2003 as final candidates.

\subsection{Analyses for the Selection of the Best Representative Year}

The systematic initial screening analysis described in the previous section clearly indicated that of the 22 candidate planning years that were evaluated, only the two candidates of Oct2002 (October 2002-September 2003) and Jan2003 (January 2003-December 2003) passed both the total annual volume and total annual event frequency screening criterion.

\subsubsection{Evaluation of Precipitation Volume}

Precipitation volume statistics are important rainfall parameters used in determining the required size of alternative wet weather control facilities and to evaluate the long term performance of the facilities. The total annual precipita- 
tion volume was analyzed for the $60 \mathrm{y}$ rainfall record available at the airport gauge.

Figure 26.7 shows a typical example of a cumulative distribution function (CDF) plot used to represent the individual storm analyses performed for one of the planning basins. Similar CDF plots were developed for all eight planning basins comparing the candidate planning year's event distribution to the historical event distribution.

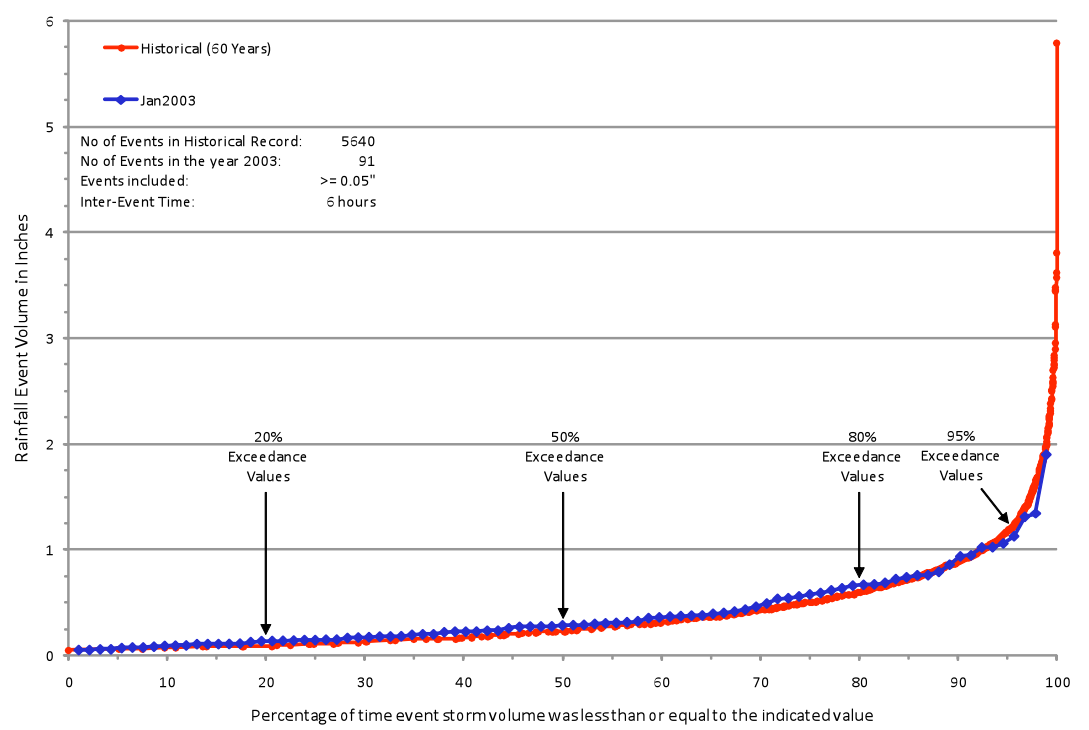

Figure 26.7 Event volume CDF plot for basin A comparing Jan2003 planning year with the historical event distribution.

The CDF plots indicate the distribution of small, medium, and large volume storms that occurred throughout the analysis period. The 5640 events $(>0.05$ in. minimum threshold value) from the historical airport record were sorted in ascending order and assigned an exceedance frequency value. Similarly the Oct2002 and Jan2003 events were sorted and assigned exceedance frequencies. Similar analyses were conducted for each of the planning basins. The $20 \%$, $50 \%, 80 \%$ and $95 \%$ event volume exceedance values from the CDF analyses were compared to the historical exceedance values. The storm volume distribution for Jan2003 had a slightly better correlation to historic record values than the storm volume distribution for Oct2002. 
Figure 26.8 shows the comparison of monthly rainfall volume for each planning basin to average historical monthly rainfall volume. Also shown are the $\pm 10 \%$ band for the average historical monthly volume. This analysis was performed on all the planning years and as it can be seen from Figure 26.8, the Jan2003 monthly frequencies are very close to the historical average and only two months lay outside $10 \%$ of the historical average.

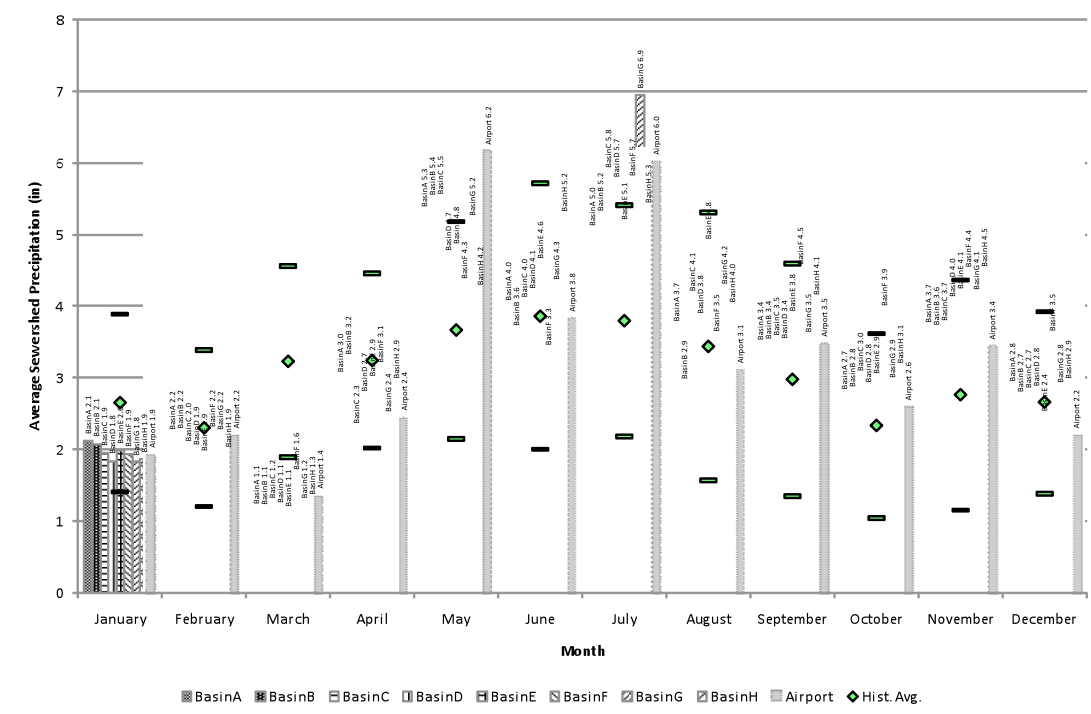

Figure 26.8 Comparison of monthly rainfall volume for each planning basin with average historical monthly volume (Jan.-Dec. 2003).

\subsubsection{Evaluation of Peak Hourly Event Intensity}

The peak hourly intensity statistics are important rainfall parameters used to determine hydraulic conveyance capacities and sizes for alternative treatment and conveyance wet weather control facilities. The hourly records from the airport gauge data were analyzed by identifying and sorting in ascending order the peak hourly intensities over the $60 \mathrm{y}$ of record. A CDF plot was generated for the historic record peak hourly intensity values from the period of record. The median or $50 \%$ exceedance value for peak hourly rainfall intensity was determined to be $0.10 \mathrm{in}$./h. Figure 26.9 shows a CDF plot for basin A comparing historical peak intensities to the Jan2003 event peaks. These plots were generated for all eight planning basins for both candidate planning years. As it 
can be seen from this sample plot for one basin, a few basins did not have the desired match at the $95 \%$ to $99 \%$ range. A second analysis was conducted to further analyze the largest event peaks explained in the next paragraph.

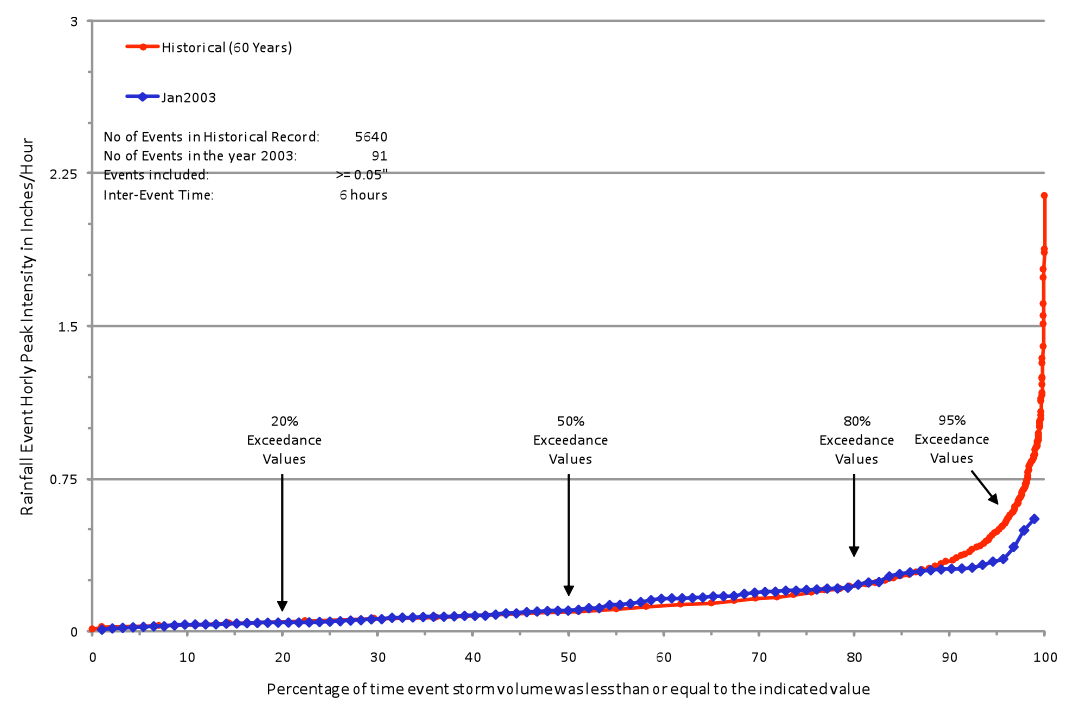

Figure 26.9 Event hourly peak CDF plot for basin A comparing Jan2003 planning year with the historical event distribution.

A second analysis of the airport gauge was conducted whereby the largest peak hourly intensity value was identified for each of the $60 \mathrm{y}$ of record and an average annual value was calculated. The process was repeated for the second and third highest peak hourly intensities and so on to quantify the 20 largest average annual peak hourly intensities. The spatially distributed virtual gauge catchment rainfall record from the regional rainfall system was analyzed for Jan2003. Peak hourly intensities were calculated from the 15 min rainfall records by summing four consecutive time-step values. CDF plots were generated and the 20 largest average annual peak hourly intensities were calculated for each of the planning basins.

Figure 26.10 shows the bar charts comparing the peak hourly intensities from the largest 20 events in the Jan2003 dataset for all planning basins. Also shown on the plot are the historical median event peak hourly intensity for that event along with the $\pm 15 \%$ guidelines. This analysis was performed on both candidate planning years and clearly the Jan 2003 largest 20 events were very 
close to the historical median peak hourly intensities further validating that the planning year Jan 2003 to be the closest to the historical average hydrological conditions.

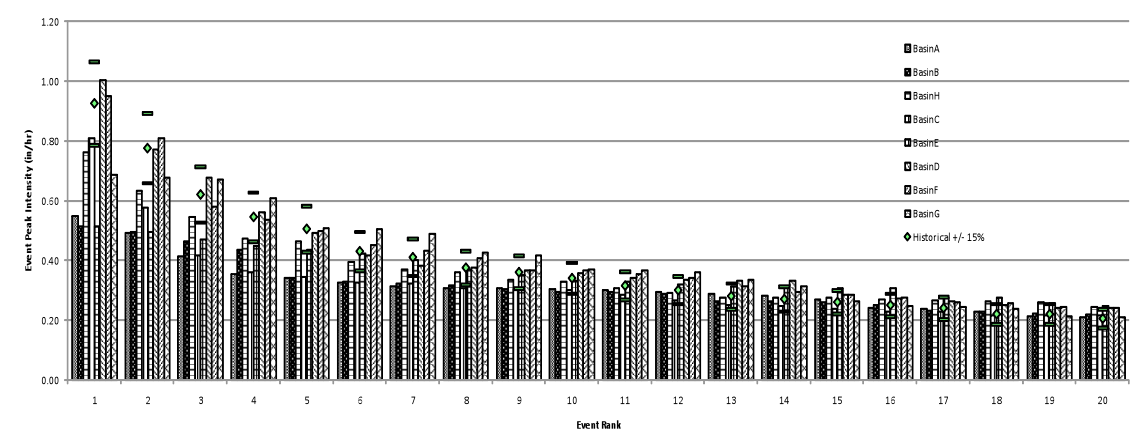

Figure 26.10 Comparing historical median peaks with Jan2003 largest event peaks for the largest 20 events.

\subsubsection{Evaluation of Precipitation Event Frequency}

Storm frequency statistics are important precipitation parameters for evaluating the performance of existing systems and proposed alternative control measures. Baseline condition analyses for the frequency of CSO discharges are directly influenced by the annual frequency or number of significant storm events in the representative year. Any bias in event frequency in the typical precipitation year data sets could cause a corresponding bias in the results of the baseline condition CSO discharge frequency analyses. The number of annual storm events was evaluated for $60 \mathrm{y}$ record from the airport gauge for three different minimum threshold values.

The number of annual storm events for precipitation year 2003 had an excellent correlation with the historical record average. The number of annual storms over all the planning basin areas, and over the airport gauge, was within the $68 \%$ confidence limit values from the historical record statistics.

Figure 26.11 shows the comparison of monthly event frequency for each planning basin to average historical monthly frequency. Also shown are the $\pm 10 \%$ bands for the average historical monthly frequency. This analysis was performed on all the planning years and as it can be seen from Figure 26.11, the Jan2003 monthly frequencies are very close to the historical average and only two months lay outside $10 \%$ of the historical average. 


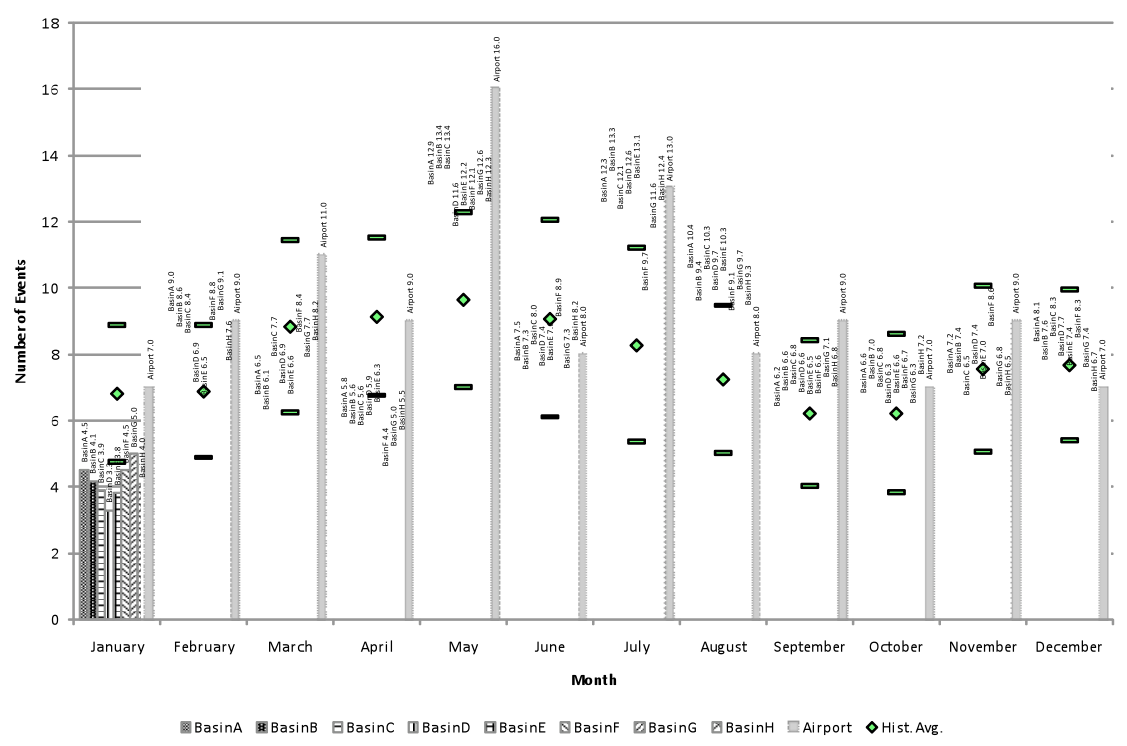

Figure 26.11 Comparison of monthly event frequency for each planning basin with average historical monthly frequency (2003).

\subsection{Conclusions}

All the statistical analyses on event statistics such as volume, peaks, duration and IETs along with the monthly volume and frequency distributions and the largest 20 events volumes and peaks comparisons to historical average suggested the planning year Jan2003 (Jan 2003-December 2003) best matches the historical average.

The calendar year 2003 spatially distributed precipitation record from the regional radar rainfall system is the representative or typical year precipitation for this service area. It has a good statistical correlation to historical average values for event volumes associated with larger annual storms, monthly volume distribution, and hourly peak intensities associated with larger annual storms. With selected adjustments to the dataset to minimize statistical bias, the 2003 precipitation record should provide a realistic basis for determining existing condition baseline statistics and as a basis for developing and assessing alternative wet weather control measures. 


\section{References}

EPA Combined Sewer Overflow (CSO) Control Policy, April 1994, EPA 830-B-94-001. Martens, G. and J. Smullen. 2004. "Normalizing Rain Gauge Network Biases with Calibrated Radar Rainfall Estimates." Journal of Water Management Modeling R223-16. doi: 10.14796/JWMM.R223-16.

Meeneghan, T., T. Prevost and K. Khan. 2002. "Impacts of Rainfall Date on Model Refinement in Greater Pittsburgh." Journal of Water Management Modeling R223-18. doi: 10.14796/JWMM.R223-18. 